\title{
Celebrating a prospective randomised control trial
}

\author{
M. Felix Freshwater \\ Voluntary Professor of Surgery, University of Miami School of Medicine, 9100 S. Dadeland Blvd. Suite 502 Miami FL 33156- \\ 7815 , USA
}

Address for correspondence: Prof. M. Felix Freshwater, Voluntary Professor of Surgery, University of Miami School of Medicine, 9100 S. Dadeland Blvd. Suite 502 Miami FL 33156-7815, USA. E-mail: mff@miami-hand.com

am writing this commentary on April 1, which is called April Fool's Day in the United States. Historically it is a day for pranks being played on persons, in print, and now even online. ${ }^{[1-4]}$

If I were to state that the preceding article was of a higher evidence-based medicine quality than the latest article on the subject to appear in the Journal of Hand Surgery, you would think that I was pulling an April Fool's prank on you.

It is no prank. It is the truth. Published ahead of print and available online at the Journal of Hand Surgery, although not yet indexed in PubMed, is a retrospective study from the Harvard Medical School/Massachusetts General Hospital. ${ }^{[5]}$

The importance of this study in the Indian Journal of Plastic Surgery cannot be sufficiently underscored. Why?

Not only is it a higher quality study than the one from the Massachusetts General Hospital, but I also discovered, by using the PubMed database, that this is the first randomised controlled blinded trial to be published in this journal.

What is most impressive is that the authors began this study almost ten years ago, before the concept of evidencebased medicine became au courant among our confreres.

One could quibble with some aspects of the methodology,

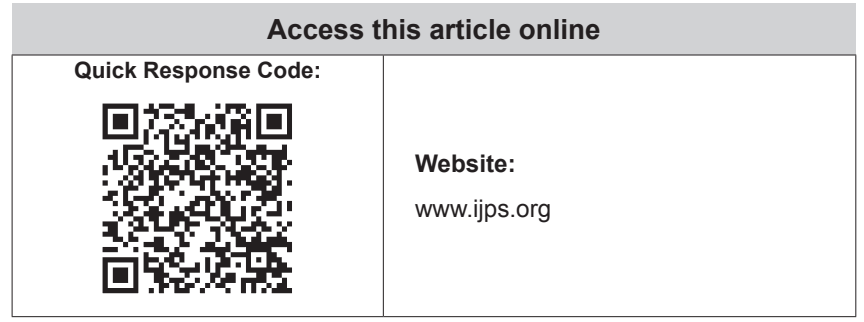

Indian Journal of Plastic Surgery January-April 2012 Vol 45 Issue 1 for example, allocating alternating patients to the control and treatment arms, was pseudo-randomisation. ${ }^{[6]}$ In 2012, random number generators are freely available on the internet. Nevertheless, the points worth noting about this study are:

1. That the authors sought to answer a meaningful clinical question rather than continue to employ the dogma that they had learned from their professors

2. That the authors proceeded in an ethical manner by obtaining approval from their institutional ethics committee

3. That the authors clearly described the informed consent that they obtained from their patients

4. That the results were measured by an independent therapist who was blinded to the treatment arms

The ethical standards that the authors maintained were those included in the Declaration of Helsinki. The only ethical requirement that the authors did not fulfil, which the IJPS and the Declaration of Helsinki now require is that all prospective trials be registered in a publicly accessible database before the first patient is enrolled. ${ }^{[7]}$ The trial registration is free.

With the wealth of patients needing treatment for their hand problems, Indian plastic surgeons have a golden opportunity to not only help their patients, but also to answer important clinical questions with high quality, ethical, prospective, blinded randomised controlled trials. ${ }^{[8]}$

These authors have been Indian pioneers. Other should follow in their footsteps.

\section{REFERENCES}

1. Freshwater MF. Mission mania. J Plast Reconstr Aesthet Surg 
2009;62:855-7.

2. Freshwater MF. Plastic haikus. J Plast Reconstr Aesthet Surg 2010;63:1068-9.

3. Freshwater MF. YAPS - Yale American Plastic Surgery Dictionary. J Plast Reconstr Aesthet Surg 2011;64:561-2.

4. Freshwater MF. "Plastic Consumation" [sic] and the "search for surgical truth". J Plast Reconstr Aesthetic Surg 2012;65:543-5.

5. Neuhaus V, Wong G, Russo KE, Mudgal CS. Dynamic Splinting With Early Motion Following Zone IV/V and TI to TIII Extensor Tendon Repairs a level IV retrospective study of 16 patients followed for an average of 96 days. J Hand Surg 2012;37:933-7. Epub 2012 Mar 30.
6. Freshwater MF. The top 10 plastic surgery research mistakes what they are and how to avoid them. J Plast Reconstr Aesthet Surg 2009;62:1709-11.

7. Freshwater MF. "Informed Consent" does not inform the readers - complying with the Journal's ethical standards and the Declaration of Helsinki. Plast Reconstr Surg 2011;128:577e.

8. Freshwater MF. Hand 2061. Indian J Plast Surg 2011;44:368-70.

How to cite this article: Freshwater MF. Celebrating a prospective randomised control trial. Indian J Plast Surg 2012;45:38-9.

Source of Support: Nil, Conflict of Interest: None declared.

\section{Dispatch and return notification by E-mail}

The journal now sends email notification to its members on dispatch of a print issue. The notification is sent to those members who have provided their email address to the association/journal office. The email alerts you about an outdated address and return of issue due to incomplete/incorrect address.

If you wish to receive such email notification, please send your email along with the membership number and full mailing address to the editorial office by email. 